\title{
Educational differences in self-rated physical fitness among Finns
}

\author{
Kaisa R Pulkkinen ${ }^{1 *}$, Tomi Mäkinen ${ }^{2}$, Heli Valkeinen ${ }^{2}$, Ritva Prättälä ${ }^{3}$ and Katja Borodulin ${ }^{1}$
}

\begin{abstract}
Background: The high educated live longer and healthier lives when compared to the low educated. Physical fitness as a health indicator reflects the level of physical activity along with other health-influencing factors such as obesity, smoking, chronic diseases and individual training effects. Studies support that self-rated physical fitness correlates with objectively measured physical fitness well. However, the educational differences in self-rated physical fitness are not known.

Methods: Our aim was to study educational differences in self-rated physical fitness in Finnish population. The data were collected in 2007 for a cross-sectional population based National FINRISK Study. The analyzed data included 2722 men and 3108 women aged 25 to 74 years. Statistical method was ordinal logistic regression.

Results: Longer educational career was associated with better self-rated physical fitness. The educational differences in self-rated physical fitness were largely explained by health behavior. Leisure-time physical activity explained fully and body mass index partly the educational differences in self-rated physical fitness among men. The combination of body mass index, history of chronic diseases and smoking explained the differences fully among men and partly among women. Leisure-time, occupational and commuting physical activities, body mass index, history of chronic diseases and smoking together explained all educational differences in self-rated physical fitness among both genders.
\end{abstract}

Conclusions: Although educational differences in self-rated physical fitness were found, they were explained by health behavior related factors. Leisure-time physical activity offered the strongest single explanation for the educational differences in self-rated physical fitness. Thus, possibilities for leisure-time physical activity should be increased especially among the low educated.

Keywords: Physical fitness, Physical activity, Socioeconomic position, Public health, Health

\section{Background}

Socioeconomic position (SEP) reflects individual's social and economic location in the structures of society. Karl Marx and Max Weber created the basics for the understanding of socioeconomic differences [1] and both traditions contributed to the modern research on health and socioeconomic circumstances. The aspects of wealth and working conditions can be seen largely of Marxian and the aspects of non-material resources and inequalities more of Weberian heritage. In this article the social stratification is described with SEP, since it reflects both Marxian and Weberian traditions [2].

\footnotetext{
* Correspondence: kaisa.pulkkinen@thl.fi

${ }^{1}$ Department of Chronic Disease Prevention, National Institute for Health and Welfare, PO Box 30, FIN-00271, Helsinki, Finland

Full list of author information is available at the end of the article
}

Physical fitness (PF) is "a set of health or skill related attributes that people have or can achieve" [3]. A person with good PF integrates the use of the attributes effectively to reach an optimal performance. As a result PF enables "to carry out daily tasks with vigour and alertness without undue fatigue and ample energy to enjoy leisure-time pursuits and meet unforeseen emergencies" and "to achieve the optimal quality of life" [4] Physical activity (PA) is defined as "any bodily movement produced by skeletal muscles, that results in energy expenditure" [3].

Those in higher SEP have longer and healthier lives compared to those in lower SEP $[1,5,6]$. PA is a wellknown contributor to good health [7-9] and the main way to improve PF $[3,4,8,10]$, when performed regularly in adequate amounts and proper intensities $[8,11]$. In 
addition to PA, PF is also influenced by energy balance, smoking, chronic diseases [10] as well as individual training effects and characteristics that includes genetic variability [12-15]. PF enhancing health behavior is more common in higher than lower socioeconomic groups. For example, those in higher SEP have higher PA levels [16-22], less obesity [23-25], smoke less [24,26,27] and have less chronic diseases $[28,29]$ than those in lower SEP.

Health-related PF is a combination of cardiovascular endurance, body composition, muscular strength, muscular endurance and flexibility [3]. Good PF is inversely associated with mortality and chronic morbidity $[10,12]$. It has associations also with better lipid and lipoprotein profile, lower blood pressure, better body composition, lower inflammation levels, improved autonomic nervous system [10] and improved insulin sensivity $[10,30]$. To have an overall picture of health-related PF, all components should be measured [4]. The use of self-rated PF (SRPF) might be a useful option in population based studies, since measuring objectively all PF dimensions is time consuming and expensive. Studies support that SRPF correlates with objectively measured PF rather well [31-33].

In this study, we used birth cohort adjusted years of education to indicate SEP. Education is widely used in health-related research because it reflects both material and immaterial resources such as skills, knowledge, attitudes and values [1,2]. Education is also an important indicator of life course influences as childhood circumstances often influence adult education levels [2]. Furthermore, education is a strong determinant of occupational status, working conditions and income $[1,2,34]$. It is usually also more reliably reported than e.g. income levels [2].

While the educational differences in PA have been reported in detail $[16,20,21]$, associations of education and PF have remained largely unexplored. Our purpose was to explore whether SRPF is associated with age and education and to examine whether PA, body mass index (BMI), history of chronic diseases and smoking contribute to the possible association of education and SRPF. We assumed that the young report more good PF levels than the elderly and that those with less education report more poor PF levels than those with longer educational career [35]. We assumed also that leisuretime PA (LTPA) and BMI would contribute to the educational differences in SRPF, because low LTPA levels [17-19] as well high BMI [23] are more common in lower than higher educational groups, and both of them are known to correlate with SRPF [36].

\section{Methods}

\section{Design and data collection}

The data were collected in spring 2007 for a cross-sectional population based National FINRISK Study [37] that was conducted by the former National Public Health Institute, currently The National Institute for Health and Welfare. A stratified random sample was drawn from the population register with stratifications of sex, 10-year age groups and five geographical areas. Data were collected via selfadministered questionnaires and health examinations carried out by trained nurses. The total sample size was 10000 of which $6258(62.6 \%)$ persons filled out the questionnaire and participated in the health examination. Participants were excluded, if they had missing data. The final data included 2722 men and 3108 women (total of 5830) aged 25 to 74 years. The entire study protocol followed the WHO MONICA protocol [38] and later the recommendations of the European Health Risk Monitoring Project [39]. The Ethics Committee of the Hospital District of Helsinki and Uusimaa approved the study protocol and the participants provided a written consent.

\section{Measurements}

\section{Self-rated physical fitness and education}

The dependent variable was SRPF. PF was measured with a question of "How do you consider your current physical fitness?" The answer categories were very good, quite good, fair, quite bad and very bad. The two last categories were combined for the analyses because of the small sample size in the last category. The education level was assessed by a question of "How many years have you attended school and studied full-time (basic levels included)?" The birth cohort adjusted education thirds were labeled low, middle and high.

\section{Physical activity}

Three modes of PA were inquired via questionnaire. Commuting PA (CPA) was measured with a question of "How many minutes do you walk, ride on bicycle or otherwise exercise to get to work?" Instructions guided to take into account both travelling to and from work. The answer categories were combined for the analyses into three groups: 30 minutes or more in a day, less than 30 minutes a day or no CPA at all. The question of LTPA combined the type, intensity and amount of LTPA. The question was "How much do you exercise and stress yourself physically in your leisure time?" The additional instructions guided to choose the average LTPA level, if the activity varies much according to different seasons. The answers were categorized in to three categories of high, medium and low activity levels. Occupational PA (OPA) was measured with a question: "How demanding is your work physically?" Instructions guided to choose sedentary work, if the person is not working at all. The answers were categorized into three groups: heavy, moderate and light work. 


\section{Confounding factors}

The information about age and gender was received from the population register. Age was used in the analyses as a continuous variable. The height and weight were measured in the health examination. For BMI the weight in kilograms was divided by squared height in meters $\left(\mathrm{kg} / \mathrm{m}^{2}\right)$. The questionnaire included questions about chronic diseases that had been diagnosed by a physician. Chronic diseases comprised asthma, cancer, cardiovascular diseases (myocardial infarction, stroke, cerebral hemorrhage, obstruction of a cerebral vessel, coronary bypass surgery, coronary angioplasty, hypertension, cardiac insufficiency, angina pectoris), diabetes, chronic obstructive pulmonary disease, rheumatoid arthritis, degenerative arthritis of the back or other joint or back related chronic diseases. The participants were divided into two categories: those who reported at least one chronic disease and others. Smoking was assessed in the questionnaire by questions of how often and how much the participant smoked and when was the last time he or she had smoked. The answers were categorized into three groups: non-smokers, former smokers and daily smokers. If participants reported occasional smoking that had never been regular, they were categorized into non-smokers.

\section{Statistical analyses}

The analyses were performed by ordinal logistic regression with logit -link function. The statistical software was PASW/SPSS Statistics 18 for Windows (Armonk, NY, USA). Since PASW/SPSS does not print odds ratios (OR) they were calculated in Microsoft Word Excel 2003 for Windows (Redmond WA, USA). The assumptions for the analysis were tested and fulfilled. The parallel lines assumption was tested by a random sample of $3 \%$ of the data [40]. The results are reported in ORs separately for women and men.

\section{Results}

Age and education associations with self-rated physical fitness

Mean age was 49.7 years (Standard deviation (SD) 13.9) among women and 51.2 years (SD 13.8) among men (Table 1). Age had an inverse association with SRPF in the unadjusted analyses. The elderly were more likely to report poor PF when compared to younger adults (Table 2). Education was directly associated with SRPF in the unadjusted and age adjusted analyses (Tables 2 and 3 ). Those in the high education third reported better PF than those the in low education third (Table 3).

\section{The mediating effect of physical activity}

LTPA had a strong gradient association with SRPF in the unadjusted analyses (Table 2). The odds of reporting poor PF was more than 17 times (OR 17.82, 95\% Confidence Interval (CI) 14.17-22.44) more likely for women with low LTPA than those with high LTPA levels. The strong association was also seen among men (OR 14.72, 95\%CI 11.67-18.58). Even with medium LTPA levels the odds of reporting poor SRPF was higher among women (OR 4.18 95\%CI 3.50-4.99) and men (OR 5.02 95\%CI 4.18-6.03), when compared to those with high LTPA levels. Also those with low level of OPA and CPA reported poorer PF levels than their physically most active counterparts.

In the adjusted analyses LTPA explained the educational differences in SRPF among men. However, among women the educational differences remained statistically significant (Table 3). OPA increased somewhat the educational differences in SRPF between the low and high education thirds. The combined adjustments for all modes of PA did not offer any additional information for the only LTPA adjusted model.

\section{The mediating effects of body mass index, history of chronic diseases and smoking}

Average BMI was $26.7 \mathrm{~kg} / \mathrm{m}^{2}$ (SD 5.4, range 16.4$53.1 \mathrm{~kg} / \mathrm{m}^{2}$ ) among women and $27.4 \mathrm{~kg} / \mathrm{m}^{2}$ (SD 4.2 range $16.0-63.3 \mathrm{~kg} / \mathrm{m}^{2}$ ) among men (Table 1). High BMI increased the odds for poor SRPF (Table 2). The likelihood to report poor SRPF was higher among overweight men (OR 1.79, 95\%CI 1.52-2.12) and women (OR 2.28, 95\%CI 1.95-2.66) and among obese men (OR 4.31, 95\%CI 3.51-5.30) and women (OR 6.0, 95\%CI, 4.99-7.20). Those with chronic diseases were more likely to report poor PF than the healthy. Regular daily smoking was associated more often with poor SRPF when compared to nonsmokers. Among men also former regular smoking increased the odds for poor SRPF, but among women the association was statistically non-significant.

BMI explained the educational differences in SRPF between the middle and high educational thirds among men (Table 3). However, the educational difference remained statistically significant between the low and high educational thirds among men and between all educational thirds among women. Chronic diseases or regular smoking did not contribute statistically significantly to the age adjusted educational differences in SRPF although minor decreases were seen especially when adjusted for chronic diseases. The combination of BMI, chronic diseases and smoking explained all educational differences among men and the educational difference of the high and middle educational thirds among women.

\section{The final model}

The combination of age, three types of PA, BMI, smoking status and history of chronic diseases status explained all 
Table 1 Descriptive characteristics of the participants $(n=5830)$

\begin{tabular}{|c|c|c|c|c|c|}
\hline & & \multicolumn{2}{|c|}{ Women $(n=3108)$} & \multicolumn{2}{|c|}{ Men $(n=2722)$} \\
\hline & & $\%$ or mean & $\overline{(n \text { or } S D)}$ & $\%$ or mean & ( $\mathrm{n}$ or $\mathrm{SD})$ \\
\hline Age group & $25-34$ & 18.1 & $(412)$ & 15.1 & $(562)$ \\
\hline \multirow[t]{4}{*}{$\%$} & $35-44$ & 19.9 & (509) & 18.7 & (619) \\
\hline & $45-54$ & 21.5 & (564) & 20.7 & (668) \\
\hline & $55-64$ & 20.9 & (624) & 22.9 & (649) \\
\hline & $65-74$ & 19.6 & (613) & 22.5 & (610) \\
\hline Self-rated physical fitness & Poor & 11.9 & (370) & 12.2 & (333) \\
\hline \multirow[t]{3}{*}{$\%$} & Fair & 40.1 & $(1245)$ & 40.2 & $(1095)$ \\
\hline & Good & 42.5 & (1320) & 39.6 & $(1079)$ \\
\hline & Very good & 5.6 & (173) & 7.9 & (215) \\
\hline Education thirds ${ }^{1}$ & High & 16.88 & (3.08) & 16.29 & $(2.79)$ \\
\hline \multirow[t]{2}{*}{ mean years (SD) } & Middle & 12.68 & $(2.71)$ & 11.40 & $(2.42)$ \\
\hline & Low & 9.97 & $(2.50)$ & 9.01 & $(2.12)$ \\
\hline Commuting PA & $\geq 30 \mathrm{~min}$ & 16.7 & (520) & 10.5 & (285) \\
\hline \multirow[t]{2}{*}{$\%$} & $<30 \min$ & 27.1 & (841) & 25.3 & $(690)$ \\
\hline & Inactive & 56.2 & $(1747)$ & 64.2 & $(1747)$ \\
\hline Leisure time PA & High & 25.5 & (792) & 28.3 & (770) \\
\hline \multirow[t]{2}{*}{$\%$} & Medium & 54.9 & (1706) & 51.1 & (1391) \\
\hline & Low & 19.6 & (610) & 20.6 & $(561)$ \\
\hline Occupational PA & Heavy & 16.6 & (516) & 28.6 & (778) \\
\hline \multirow[t]{2}{*}{$\%$} & Moderate & 27.3 & (850) & 20.3 & (553) \\
\hline & Light & 56.0 & $(1742)$ & 51.1 & (1391) \\
\hline BMI & $<25$ & 44.4 & $(1381)$ & 29.6 & (806) \\
\hline \multirow[t]{2}{*}{$\%$} & $25-29.9$ & 33.0 & $(1026)$ & 48.7 & (1326) \\
\hline & $\geq 30$ & 22.6 & (701) & 21.7 & $(590)$ \\
\hline Chronic Diseases ${ }^{2}$ & No & 58.1 & $(1806)$ & 53.8 & $(1464)$ \\
\hline$\%$ & Yes & 41.9 & $(1302)$ & 46.2 & (1258) \\
\hline Smoking & Never & 63.5 & (1973) & 43.6 & $(1188)$ \\
\hline \multirow[t]{2}{*}{$\%$} & Former & 19.6 & (609) & 32.2 & (876) \\
\hline & Daily & 16.9 & $(526)$ & 24.2 & $(658)$ \\
\hline
\end{tabular}

1) education represented in mean years (standard deviation in parentheses).

2) asthma, cancer, cardiovascular diseases, diabetes, chronic obstructive pulmonary disease, rheumatoid arthritis, degenerative arthritis of the back or other joint or back related chronic diseases.

educational differences in SRPF among both genders (Table 3). Compared to the high educated, the odd ratios for the middle and low educated women were $1.13(95 \%$ CI 0.95-1.34), 1.17 (95\% CI 1.00-1.42, p=0.057) and for middle and low educated men 0.97 (95\% CI 0.81-1.16), 0.97 (95\% CI 0.78-1.18), respectively.

\section{Interactions}

The variables LTPA, CPA, BMI and education had statistically significant interactions with each other. The directions of the associations were same as in main effects: less PA, higher BMI and lower education were associated with poorer SRPF.

\section{Discussion}

Our purpose was to explore whether SRPF is associated with age and education and to examine whether PA, BMI, history of chronic diseases and smoking contribute to the possible association of education and SRPF. Our large population based data supported our hypotheses and suggested that age was inversely associated with SRPF. Education was directly associated with SRPF, and these educational differences were explained by health behavior related factors. LTPA, the strongest single contributor, explained fully and BMI partly the educational differences in SRPF among men. The combination of BMI, history of chronic diseases and smoking explained 
Table 2 Crude odds ratios (OR) for poor self-rated physical fitness

\begin{tabular}{|c|c|c|c|c|c|c|c|c|c|}
\hline \multirow[t]{2}{*}{ Variables } & & \multicolumn{4}{|c|}{ Women $(n=3108)$} & \multicolumn{4}{|c|}{ Men $(n=2722)$} \\
\hline & & $\mathrm{n}$ & Poor fitness $\mathrm{n}(\%)$ & OR & $95 \% \mathrm{Cl}$ & $\mathrm{n}$ & Poor fitness $\mathbf{n}(\%)$ & OR & $95 \% \mathrm{Cl}$ \\
\hline \multirow[t]{5}{*}{ Age group (years) } & $25-34$ & 562 & $49(8.7)$ & 1.00 & (ref) & 412 & $25(6.1)$ & 1.00 & (ref) \\
\hline & $35-44$ & 619 & $74(12.0)$ & 1.29 & $1.04-1.59$ & 509 & $56(11.0)$ & 1.28 & $1.01-1.64$ \\
\hline & $45-54$ & 668 & $94(14.1)$ & 1.54 & $1.24-1.90$ & 564 & $76(13.5)$ & 1.59 & $1.25-2.02$ \\
\hline & $55-64$ & 649 & $80(12.3)$ & 1.73 & $1.39-2.13$ & 624 & $99(15.9)$ & 1.97 & $1.56-2.49$ \\
\hline & $65-74$ & 610 & $73(12.0)$ & 1.94 & $1.57-2.42$ & 613 & 77 (12.6) & 1.96 & $1.55-2.48$ \\
\hline \multirow[t]{3}{*}{ Education thirds } & High & 1079 & $109(10.1)$ & 1.00 & (ref) & 973 & $108(11.1)$ & 1.00 & (ref) \\
\hline & Middle & 1036 & $117(11.3)$ & 1.23 & $1.04-1.44$ & 963 & $126(13.1)$ & 1.26 & $1.06-1.49$ \\
\hline & Low & 993 & $144(14.5)$ & 1.54 & $1.31-1.81$ & 786 & $99(12.6)$ & 1.39 & $1.17-1.65$ \\
\hline \multirow[t]{3}{*}{ Commuting PA } & $\geq 30 \mathrm{~min}$ & 520 & $30(5.8)$ & 1.00 & (ref) & 285 & $22(7.7)$ & 1.00 & (ref) \\
\hline & $<30 \min$ & 841 & $99(11.8)$ & 1.50 & $1.22-1.84$ & 690 & $69(10.0)$ & 1.07 & $0.82-1.38$ \\
\hline & Inactive & 1747 & $241(13.8)$ & 1.97 & $1.63-2.37$ & 1747 & $242(13.9)$ & 1.48 & $1.18-1.88$ \\
\hline \multirow[t]{3}{*}{ Leisure time PA } & High & 792 & $9(1.1)$ & 1.00 & (ref) & 770 & $14(1.8)$ & 1.00 & (ref) \\
\hline & Medium & 1706 & $158(9.3)$ & 4.18 & $3.50-4.99$ & 1391 & $139(10.0)$ & 5.02 & $4.18-6.03$ \\
\hline & Low & 610 & $203(33.3)$ & 17.82 & $14.17-22.44$ & 561 & $180(32.1)$ & 14.72 & $11.67-18.58$ \\
\hline \multirow[t]{3}{*}{ Occupational PA } & Heavy & 516 & $52(10.1)$ & 1.00 & (ref) & 778 & $65(8.4)$ & 1.00 & (ref) \\
\hline & Moderate & 850 & $78(9.2)$ & 0.91 & $0.74-1.12$ & 553 & $47(8.5)$ & 0.99 & $0.80-1.20$ \\
\hline & Light & 1742 & $240(13.8)$ & 1.37 & $1.14-1.65$ & 1391 & $221(15.9)$ & 1.53 & $1.29-1.80$ \\
\hline \multirow[t]{3}{*}{ Body mass index $\left(\mathrm{kg} / \mathrm{m}^{2}\right)$} & $<25$ & 1381 & $77(5.6)$ & 1.00 & (ref) & 806 & $51(6.3)$ & 1.00 & (ref) \\
\hline & $25-29.9$ & 1026 & $110(10.7)$ & 2.28 & $1.95-2.66$ & 1326 & $136(10.3)$ & 1.79 & $1.52-2.12$ \\
\hline & $\geq 30$ & 701 & $183(26.1)$ & 6.00 & $4.99-7.20$ & 590 & $146(24.7)$ & 4.31 & $3.51-5.30$ \\
\hline \multirow[t]{2}{*}{ Chronic diseases ${ }^{1)}$} & No & 1806 & $138(7.6)$ & 1.00 & (ref) & 1464 & $97(6.6)$ & 1.00 & (ref) \\
\hline & Yes & 1302 & $232(17.8)$ & 2.60 & $2.27-2.99$ & 1258 & $236(18.8)$ & 2.61 & $2.26-3.01$ \\
\hline \multirow[t]{3}{*}{ Smoking } & Never & 1973 & $213(10.8)$ & 1.00 & (ref) & 1188 & $101(8.5)$ & 1.00 & (ref) \\
\hline & Former & 609 & 77 (12.6) & 1.04 & $0.88-1.24$ & 876 & $128(14.6)$ & 1.61 & $1.37-1.90$ \\
\hline & Daily & 526 & $80(15.2)$ & 1.32 & $1.10-1.58$ & 658 & $104(15.8)$ & 1.87 & $1.56-2.23$ \\
\hline
\end{tabular}

Self-rated physical fitness categories are poor, fair, good and very good.

$P A=$ physical activity, $\mathrm{Cl}=$ confidence interval.

1) asthma, cancer, cardiovascular diseases, diabetes, chronic obstructive pulmonary disease, rheumatoid arthritis, degenerative arthritis of the back or other joint or back related chronic diseases.

all educational differences in SRPF, except for the low educated women. The combination of age, three modes of PA, BMI, smoking status and history of chronic diseases explained all educational differences in SRPF among both genders. The strengths of this study are a representative population sample and education as the main indicator of SEP. The response rate of FINRISK 2007 study was $62.6 \%$. The participation rate was acceptable, but those who do not participate are known to be more often less educated $[41,42]$. If the participation rate would have been higher and thus the proportion of the less educated would have been higher, it is possible that the educational differences in SRPF would have been even more pronounced than reported.

According to our study, the strongest single contributor for the educational differences in SRPF was LTPA. Also previous studies support that LTPA levels are higher among the high educated when compared to the low educated $[16,18,21,24]$. Good PF is often due to high level of PA $[3,4,10]$. In addition to PA, material welfare and social influences may explain the educational differences in SRPF. Better material circumstances increase the possibility and variety to participate in LTPA among the high educated when compared to the low educated $[1,2,34,43]$. Moreover, social appreciation and support possibly gained through high education is likely to increase the participation in LTPA $[44,45]$. The low educated may also live in more deprived neighborhoods, where positive LTPA may be restricted by inadequate sports facilities, feelings of unsafe [43] or social control and norms [44].

Apart from LTPA, we found that other modes of PA could not explain the educational differences in SRPF. However, the questionnaire measured only the amount 
Table 3 Age adjusted associations of education and poor self-rated physical fitness among women and men

Education thirds

\begin{tabular}{|c|c|c|c|c|c|c|c|c|c|}
\hline \multicolumn{10}{|c|}{ Education thirds } \\
\hline \multicolumn{5}{|c|}{ Women } & \multicolumn{5}{|c|}{ Men } \\
\hline \multirow{2}{*}{$\frac{\text { High }}{\text { OR }}$} & \multicolumn{2}{|r|}{ Middle } & \multicolumn{2}{|r|}{ Low } & \multirow{2}{*}{$\frac{\text { High }}{\text { OR }}$} & \multicolumn{2}{|r|}{ Middle } & \multicolumn{2}{|r|}{ Low } \\
\hline & OR & $(95 \% \mathrm{Cl})$ & OR & $(95 \% \mathrm{Cl})$ & & OR & $(95 \% \mathrm{Cl})$ & OR & $(95 \% \mathrm{Cl})$ \\
\hline 1.00 & 1.23 & $(1.05-1.45)$ & 1.57 & $(1.33-1.84)$ & 1.00 & 1.26 & $(1.07-1.48)$ & 1.42 & $(1.19-1.69$ \\
\hline
\end{tabular}

Models and adjustments

Model 2: Physical activity (PA)

2a) Commuting PA (CPA)

$\begin{array}{llllllllll}1.00 & 1.21 & (1.03-1.43) & 1.56 & (1.32-1.83) & 1.00 & 1.23 & (1.04-1.46) & 1.38 & (1.16-1.65)\end{array}$

2b) Leisure-time PA (LTPA)

2c) Occupational PA (OPA)

$\begin{array}{llllllllll}1.00 & 1.21 & (1.02-1.43) & 1.37 & (1.16-1.62) & 1.00 & 1.01 & (0.85-1.19) & 0.99 & (0.83-1.19)\end{array}$

$\begin{array}{llllllllll}1.00 & 1.25 & (1.07-1.47) & 1.62 & (1.37-1.91) & 1.00 & 1.36 & (1.15-1.61) & 1.57 & (1.31-1.89)\end{array}$

2d) $C P A+L T P A+O P A$

$\begin{array}{llllllllll}1.00 & 1.21 & (1.02-1.43) & 1.39 & (1.17-1.65) & 1.00 & 1.08 & (0.90-1.28) & 1.10 & (0.90-1.33)\end{array}$

\section{Model 3: Health \& lifestyle}

3a) Body Mass Index (BMI)

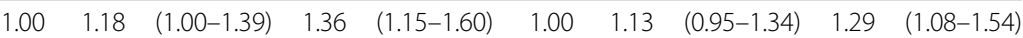

3b) Chronic diseases ${ }^{1}$

3c) Smoking

3d) $\mathrm{BMI}+$ Chronic diseases + Smoking

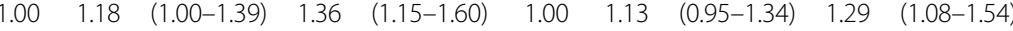

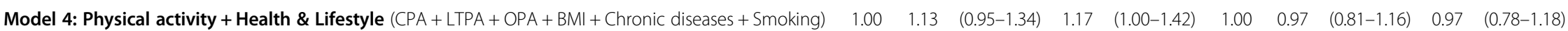

$\begin{array}{llllllllll}1.00 & 1.18 & (1.01-1.39) & 1.48 & (1.25-1.74) & 1.00 & 1.21 & (1.30-1.43) & 1.34 & (1.12-1.60)\end{array}$

$\begin{array}{llllllllll}1.00 & 1.22 & (1.04-1.43) & 1.50 & (1.27-1.77) & 1.00 & 1.20 & (1.01-1.42) & 1.28 & (1.08-1.53)\end{array}$

$\begin{array}{llllllllll}1.00 & 1.13 & (0.96-1.33) & 1.25 & (1.05-1.48) & 1.00 & 1.06 & (0.90-1.26) & 1.14 & (0.95-1.36)\end{array}$

$O R=$ odds ratio, $\mathrm{Cl}=$ confidence interval.

"asthma, cancer, cardiovascular diseases, diabetes, emphysema, rheumatoid arthritis or other joint or back related chronic diseases. 
but not the intensity of CPA. It is therefore possible that all CPA reported was not contributing to PF. For example, CPA may be performed out of necessity instead of own motivation if other types of commuting are not possible. This is likely at least, if the household cannot afford to buy and maintain a car, and the public transportation services are inadequate in the neighborhood. If CPA is performed out of necessity, the fitness promoting intensities may even be avoided especially, if the working place lacks proper changing rooms and showering facilities. In this assumption the socioeconomic differences could exist if not in the amount but in the intensity of CPA.

In our study, BMI explained educational differences in SRPF only partly and only among men. It has been studied that BMI correlates with SRPF, but when adjusted with LTPA, the association between BMI and SRPF disappears [36]. This could indicate that LTPA would be a mediating factor between BMI and SRPF at least for middle-aged male employees. It is also established that LTPA would mediate the association of BMI and SEP for women, but not for men [46]. Thus it seems that LTPA mediates the health behavior related factors which BMI influence, but mediating pathways might be different among men and women. This difference may offer some explanations for the fact that we found partial mediating effects with BMI among men but not among women, and that LTPA explained educational differences in SRPF among men but not among women.

We did not expect that the explaining factors would differ between women and men. The gender difference in the explaining factors may arise either from the different views of SRPF among women and men or from the gender difference within the actual health behavior. To our knowledge, it is not known how individuals estimate their PF. However, it is likely that they compare their abilities with a reference group, which may consist of co-workers, friends, neighborhood inhabitants, own previous PF or others of the same gender. In this respect, individual SRPF may vary a great deal according to the reference group that has been chosen. For example, comparing PF with co-workers in physically straining work is likely to produce different estimations than if the reference groups would consist mainly of those in light work. Also previous severe illnesses of very high sport participation in past may affect individual estimates of individual PF.

We assume that conceptual differences may also contribute to PF estimations. For example, men may consider PF more as physical performance and women more as general well-being. If it is assumed that men consider PF more as physical performance and women as general well-being, it is also likely that men perform
LTPA more often PF oriented and women just for having fun and enjoyment. Interestingly, according to our results, (slightly) a higher proportion of men than women considered their fitness level to be poor even when they reported high or medium LTPA levels (Table 2). Thus it is likely that some of the gender differences in our findings can be explained by conceptual differences in SRPF. It is most likely that the concept of SRPF vary also according to other attributes than gender, for example according to age or educational level.

For the future studies, more specific validation is needed to clarify the correspondence of self-rated and objectively measured PF. Also the associations of SRPF and other health measures such as self-rated health and functional ability need to be explored as well as the association of SRPF and other SEP indicators, such as income and occupation.

\section{Conclusion}

Educational differences in SRPF were found, but they could be explained by health behavior related factors. LTPA offered the strongest single explanation for the educational differences in SRPF. Enhancing LTPA among the low educated could improve public health and decrease the health inequalities between the educational groups.

\begin{abstract}
Abbreviations
SEP: Socioeconomic position; PA: Physical activity; PF: Physical fitness; SRPF: Self-rated physical fitness; BMI: Body mass index; LTPA: Leisure-time physical activity; CPA: Commuting physical activity; OPA: Occupational physical activity; SD: Standard deviation; OR: Odds ratio; Cl: Confidence interval.
\end{abstract}

\section{Competing interests}

The authors declare no competing interests.

\section{Authors' contributions}

KP carried out the analyses and drafted the manuscript with the support of KB. All authors participated in planning of the manuscript and commented the different manuscript versions of the article. In addition, TM provided his expertise in statistical methods, KB and HV their expertise in physical fitness and RP her expertise in health behavior in general and among subgroups. All of the authors have approved the final version of the manuscript.

Acknowledgements

The Ministry of Education, the Academy of Finland [\#210435] and the Research Program on "The Future of Work and Wellbeing" funded this work.

\section{Author details}

${ }^{1}$ Department of Chronic Disease Prevention, National Institute for Health and Welfare, PO Box 30, FIN-00271, Helsinki, Finland. Department of Health, Functional Capacity and Welfare, National Institute for Health and Welfare, PO Box 30, FIN-00271, Helsinki, Finland. ${ }^{3}$ Department of Lifestyle and Participation, National Institute for Health and Welfare, PO Box 30, FIN-00271, Helsinki, Finland.

Received: 8 November 2012 Accepted: 20 February 2013 Published: 22 February 2013

\section{References}

1. Lynch J, Kaplan G: Socioeconomic position. In Social Epidemiology. Edited by Berkman LF, Kawachi I. New York: Oxford University Press; 2000:13-35. 
2. Galobardes B, Lynch J, Smith GD: Measuring socioeconomic position in health research. Br Med Bull 2007, 81-82:21-37.

3. Caspersen CJ, Powell KE, Christenson GM: Physical activity, exercise, and physical fitness: definitions and distinctions for health-related research. Public Health Rep 1985, 100(2):126-131.

4. American College of Sports Medicine: ACSM's Health-Related Physical Fitness Assessment Manual. 3rd edition. Philadelphia PA: Lippincott Williams \& Wilkins; 2009.

5. UCL Institute of Health Equity: Fair Society. Healthy Lives: The Marmot Review. London; 2010

6. Prättälä R, Koskinen $\mathrm{S}$, Martelin $\mathrm{T}$, Lahelma $\mathrm{E}$, Sihto $\mathrm{M}$, Palosuo $\mathrm{H}$ : Health inequalities and the challenge of how to reduce them. In Health inequalities in Finland. Trends in socioeconomic health differences 1980-2005. Edited by Palosuo H, Koskinen S, Lahelma E, et al. Helsinki: Ministry of Social affairs and Health; 2009:11-19.

7. Nocon M, Hiemann T, Muller-Riemenschneider F, Thalau F, Roll S, Willich SN: Association of physical activity with all-cause and cardiovascular mortality: a systematic review and meta-analysis. Eur J Cardiovasc Prev Rehabil 2008, 15(3):239-246.

8. U.S. Department of Health and Human Services: Physical Activity and Health: A Report of the Surgeon General. Atlanta, GA: Department of Health and Human Services, Centers for Disease Control and Prevention, National Center for Chronic Disease Prevention and Health Promotion; 1996.

9. Fogelholm M: Physical activity, fitness and fatness: relations to mortality, morbidity and disease risk factors. A systematic review. Obes Rev 2010 11(3):202-221.

10. Lee DC, Artero EG, Sui X, Blair SN: Mortality trends in the general population: the importance of cardiorespiratory fitness. J Psychopharmacol 2010, 24(Suppl 4):27-35.

11. American College of Sports Medicine: ACSM's Guidelines for Exercise Testing and Prescription. 8th edition. Philadelphia PA: Lippincott Williams \& Wilkins; 2009

12. Church $\mathrm{T}$ : The low-fitness phenotype as a risk factor: more than just being sedentary? Obesity 2009, 17(Suppl 3):39-42.

13. Mori M, Higuchi K, Sakurai A, Tabara Y, Miki T, Nose H: Genetic basis of inter-individual variability in the effects of exercise on the alleviation of lifestyle-related diseases. J Physiol (Lond) 2009, 587(Pt 23):5577-5584.

14. Bouchard C, Rankinen T: Individual differences in response to regular physical activity. Med Sci Sports Exerc 2001, 33(6 Suppl):S446-S451.

15. Rankinen T, Bouchard C: Gene-physical activity interactions: overview of human studies. Obesity 2008, 16(Suppl 3):S47-S50.

16. Borodulin K, Laatikainen T, Lahti-Koski M, Jousilahti P, Lakka TA: Association of age and education with different types of leisure time physical activity among 4437 Finnish adults. JPAH 2008, 5(2):242-251.

17. Mäkinen TE, Sippola R, Borodulin K, Rahkonen O, Kunst A, Klumbiene J, Regidor E, Ekholm O, Mackenbach J, Prättälä R: Explaining educationa differences in leisure-time physical activity in Europe: the contribution of work-related factors. Scand J Med Sci Sports 2012, 22(3):439-447.

18. Gidlow $C$, Johnston $L$, Crone $D$, Ellis $N$, James D: A systematic review of the relationship between socioeconomic position and physical activity. Health Educ J 2006, 65(338):338-367

19. Federico B, Falese L, Marandola D, Capelli G: Socioeconomic differences in sport and physical activity among Italian adults. J Sports Sci 2012. http:// dx.doi.org/10.1080/02640414.2012.736630.

20. Mäkinen T, Borodulin K, Laatikainen T, Fogelholm M, Prättälä R: Twenty-five year socioeconomic trends in leisure-time and commuting physical activity among employed Finns. Scand J Med Sci Sports 2009, 19(2):188-197.

21. Mäkinen $T$, Kestilä L, Borodulin $K$, Martelin T, Rahkonen $O$, Leino-Arjas $P$, Prättälä R: Occupational class differences in leisure-time physical inactivity-contribution of past and current physical workload and other working conditions. Scand J Work Environ Health 2010, 36(1):62-70.

22. Lindstrom M, Hanson BS, Ostergren PO: Socioeconomic differences in leisuretime physical activity: the role of social participation and social capital in shaping health related behaviour. Soc Sci Med 2001, 52(3):441-451.

23. Reunanen A, Kattainen A, Salomaa V: Biological risk factors. In Health inequalities in Finland. Trends in socioeconomic health differences 1980-2005. Edited by Palosuo H, Koskinen S, Lahelma E, et al. Helsinki: Ministry of Social Affairs and Health; 2009:169-177.

24. Helakorpi S, Laitalainen E, Uutela A: Suomalaisen aikuisväestön terveyskäyttäytyminen ja terveys, kevät 2009 (Health Behaviour and Health among the Finnish Adult Population, Spring 2009). Helsinki, Finland: National
Institute for Health and Welfare; 2010. Report 7/2010

25. Roos E, Ovaskainen M, Raulio S, Pietikäinen M, Sulander T, Prättalä R: Dietary habits. In Health inequalities in Finland. Trends in socioeconomic health differences 1980-2005. Edited by Palosuo H, Koskinen S, Lahelma E, et al. Helsinki: Ministry of Social affairs and Health; 2009:149-158.

26. Laaksonen M, Helakorpi S, Karvonen S, Patja K, Sulander T: Smoking. In Health inequalities in Finland. Trends in socioeconomic health differences 1980-2005. Ministry of Social Affairs and Health Publications 2009. 9th edition. Edited by Palosuo H, Koskinen S, Lahelma E, et al. Helsinki: Ministry of Social affairs and Health; 2009:131-139.

27. Mackenbach JP, Stirbu I, Roskam AJ, Schaap MM, Menvielle G, Leinsalu M, Kunst AE, European Union Working Group on Socioeconomic Inequalities in Health: Socioeconomic inequalities in health in 22 European countries. $N$ Engl J Med 2008, 358(23):2468-2481.

28. Koskinen S, Martelin T, Sainio P, Heliövaara M, Reunanen A, Lahelma E: Chronic morbidity. In Health inequalities in Finland. Trends in socioeconomic health differences 1980-2005. Edited by Palosuo H, Koskinen S, Lahelma E, et al. Helsinki: Ministry of Social affairs and Health; 2009:70-82.

29. Dalstra JA, Kunst AE, Borrell C, Breeze E, Cambois E, Costa G, Geurts JJ, Lahelma E, Van Oyen H, Rasmussen NK, Regidor E, Spadea T, Mackenbach JP: Socioeconomic differences in the prevalence of common chronic diseases: an overview of eight European countries. Int J Epidemiol 2005, 34(2):316-326.

30. Borodulin K, Tuomilehto J, Peltonen M, Lakka TA, Sundvall J, Jousilahti P: Association of leisure time physical activity and abdominal obesity with fasting serum insulin and 2-h postchallenge plasma glucose levels. Diabet Med 2006, 23(9):1025-1028.

31. Knapik JJ, Jones BH, Reynolds KL, Staab JS: Validity of self-assessed physical fitness. Am J Prev Med 1992, 8(6):367-372.

32. Mikkelsson L, Kaprio J, Kautiainen $\mathrm{H}$, Kujala UM, Nupponen $\mathrm{H}$ : Associations between self-estimated and measured physical fitness among 40-year-old men and women. Scand J Med Sci Sports 2005, 15(5):329-335

33. Germain $J$, Hausenblas HA: The relationship between perceived and actual physical fitness: a meta-analysis. J App/ Sport Psychol 2006, 18:283-296.

34. Weyers S, Dragano N, Richter M, Bosma H: How does socio economic position link to health behaviour? Sociological pathways and perspectives for health promotion. Glob Health Promot 2010, 17:25-33.

35. Duetz MS, Abel T, Niemann S: Health measures. Differentiating associations with gender and socio-economic status. Eur J Public Health 2003, 13:313-319.

36. Okano G, Miyake $H$, Mori M: Leisure time physical activity as a determinant of self-perceived health and fitness in middle-aged male employees. J Occup Health 2003, 45:286-292.

37. Vartiainen $E$, Laatikainen T, Peltonen M, Juolevi A, Männistö S, Sundvall J, Jousilahti P, Salomaa V, Valsta L, Puska P: Thirty-five-year trends in cardiovascular risk factors in Finland. Int J Epidemiol 2010, 39(2):504-518. http://dx.doi.org/10.1093/ije/dyp330. First published online: December 3, 2009.

38. World Health Organization: The World Health Organization MONICA Project (monitoring trends and determinants in cardiovascular disease): a major international collaboration. WHO MONICA Project Principal Investigators. J Clin Epidemio/ 1988, 41(2):105-114.

39. Tolonen H, Kuulasmaa K, Laatikainen T, Wolf H: The European health Risk Monitoring Project. European health risk monitoring project: Recommendation for indicators, international collaboration, protocol and manual of operations for chronic disease risk factor surveys. http://www.thl.fi/publications/ehrm/ product2/title.htm

40. Garson GD: Ordinal regression. Asheboro NC: Statistical Associates Publishers; 2012

41. Harald K, Salomaa V, Jousilahti $P$, Koskinen S, Vartiainen E: Non-participation and mortality in different socioeconomic groups: the FINRISK population surveys in 1972-92. J Epidemiol Community Health 2007, 61(5):449-454.

42. Jousilahti P, Salomaa V, Kuulasmaa K, Niemela M, Vartiainen E: Total and cause specific mortality among participants and non-participants of population based health surveys: a comprehensive follow up of 54372 Finnish men and women. J Epidemiol Community Health 2005, 59(4):310-315.

43. Diez Roux AV, Mair C: Neighborhoods and health. Ann N Y Acad Sci 2010, 1186:125-145. 
44. McNeill LH, Kreuter MW, Subramanian SV: Social environment and physical activity: a review of concepts and evidence. Soc Sci Med 2006, 63(4):1011-1022.

45. Ueshima K, Fujiwara T, Takao S, Suzuki E, Iwase T, Doi H, Subramanian SV Kawachi I: Does social capital promote physical activity? A populationbased study in Japan. PLoS One 2010, 5(8):e12135.

46. Borodulin K, Zimmer C, Sippola R, Makinen TE, Laatikainen T, Prattala R: Health behaviours as mediating pathways between socioeconomic position and body mass index. Int J Behav Med 2012, 19(1):14-22.

doi:10.1186/1471-2458-13-163

Cite this article as: Pulkkinen et al:: Educational differences in self-rated physical fitness among Finns. BMC Public Health 2013 13:163.

\section{Submit your next manuscript to BioMed Central and take full advantage of:}

- Convenient online submission

- Thorough peer review

- No space constraints or color figure charges

- Immediate publication on acceptance

- Inclusion in PubMed, CAS, Scopus and Google Scholar

- Research which is freely available for redistribution 